\title{
PSS Production Systems: A Simulation Approach for Change Management
}

\author{
Guillaume Marquès, Malik Chalal, and Xavier Boucher \\ Ecole Nationale Supérieure des Mines, FAYOL-EMSE, CNRS-UMR5600, \\ EVS, F-42023 Saint-Etienne - France \\ \{gmarques, chalal, boucher\}@emse.fr
}

\begin{abstract}
The research presented in this paper is oriented on the transition of the manufacturing industry towards the delivery of product-service system. The paper presents the first results in the development of a decision support system dedicated to help in configuring service-oriented production systems, notably with an objective of capacity management. An illustrative case study is presented, linked to the production of washing machines.
\end{abstract}

Keywords: Servicization, Product Service Systems, Production System, Modelling, Simulation.

\section{Introduction}

In an increasing business competition world, industrial companies are faced to the necessity to develop strong innovations on their business models. The development of service based added-value is one of these innovations inducing progressive integration of services along the whole life-cycle of industrial offers. The transition of the manufacturing industry towards the integration of services is known in the literature as servicization [1]. It is not only a new business model, but requires strong organizational changes. Anticipating this transition is becoming crucial for decision makers (DM). The overall orientation of the research work presented, consists in developing a relevant decision support system to help managing the organizational transition. First, we present a background on PSS systems. Then, we present our proposition to model behavior of a manufacturing system faced with servitization. Section 4 proposes an industrial case study to illustrate the use of this model. The last part presents conclusions and future research works related to this approach.

\section{Background on PSS Systems}

PSS is a new concept that has emerged in the research world after the work of [2]. Here, we are interested in modeling 2 main subsystems associated to PSS literature: the user-oriented subsystem (2.1) and the production subsystem (2.2). 


\subsection{User-Oriented System}

Use is large research issue addressed through different point of view and mainly by ergonomics and marketing. Both deal with the analysis of the asset in use in order to design product with a maximum of value in use. Two main families of analysis of the user system may be identified: (i) the user's behaviour faced with the commercial offer, and (ii) the user's behaviour with the asset in use. The first one is linked to the set of PSS for which is ready to pay in order to satisfy a need. The second one is related to the need in service providing induced by the usage of the product.

A lot of studies have a macroscopic view of the user behaviour faced with commercial offer and only model a global market volume, often timely constant. However, these simulations require a high level of description of the service offer: kind of customer product segmentation, contract term [3], service providing lead time [4]... Different kind of services, called industrial services [5] main be implicated.

Life Cycle Simulation is a current approach to evaluate performance (eco. and env.) of life cycles of products in use [3]. Discreet event simulation is mainly used in this case. These kind of models are supported by a detailed description of the product and its characteristics [3, 6]: lifespan, maximum of operations per period, breakdown rate, wear-out propensity, reparability, reusability... The user is described through: a functionality need per period or usage intensity. Modeling the appearance of customer needs most often implies stochastic processes in order to characterize this uncertainty.

\subsection{PSS Oriented Production System}

To implement PSS, a manufacturing company has to develop new production capabilities, covering both new structural characteristics of the system as well as new managerial abilities. Academic and industrial contributions underline the necessity for the company to manage 2 new production areas: product remanufacturing processes on one side, and service design, production and delivery on the other side. So, the full PSS Production System has to be considered as composed of 3 sub-systems: the manufacturing (1), the remanufacturing (2) and service production (3) sub-systems.

Remanufacturing is a process in which worn-out products are restored to like-new condition [7]. A discarded product is partially or completely disassembled. Among disassembled parts, usable ones are cleaned, refurbished, and put into inventory. Then, the new product is reassembled from both old and sometimes new parts to produce a unit equivalent or superior in performance and expected lifetime to the original new product [8]. In comparison to manufacturing, it is difficult to assess the number and the timing of the returns and to preview the quality of the used products [9].

To configure a service production system, a first difficulty consists in identifying service offers which could be consistent with the strategy of the firm. The service opportunities in the context of PSS are distributed along the PSS life-cycle. In [5, 10] authors propose a typology of "industrial services". This framework emphasizes the combination of service life cycle and product life cycle. 
Capacity planning is a key strategic component in designing goods/services production system in achieving a match between the long term supply capabilities of an organization and the predicted level of long term demand. The service production area is submitted to variations of capacity needs much more notable and unpredictable than for traditional manufacturing. The classical a product stock policy optimization approach has to evolve towards the possibility to manage stocks of "capacity to deliver service". "The management of capacity is not trivial in PSS context" [11]: How should capacity level be managed to support new goods manufacturing as well as after-sales service if they share the same resources.

\section{A Modelling Approach for PSS Production Systems}

We intend to build decision aid method and tool, to support the dimensioning and evaluation of alternative configurations of a PSS production system. To study this transition of production system, this paper proposes a modelling approach dedicated to PSS Production Systems. This approach aims at implementing event driven simulation of various sub-systems of the full PSS Production System. Simulation is used as a decision support to build comparative analyses of alternative transition scenarios.

We propose, at first, a general conceptual model which considers two subsystems: the user-oriented and the production subsystems. The user-oriented subsystem represents the usage environment which generates the various demands of products and services. It is dedicated to model and simulate user behaviours which impact the production system. The production-oriented subsystem represents a set of services providing, manufacturing and remanufacturing processes. This second subsystem is dedicated to model and analyse the internal organisation, planning mechanisms, interactions and performances of both manufacturing-oriented and service-oriented processes. Decoupling two subsystems allows a twofold objective. On the one hand, both production and user oriented systems can be modelled individually with a lot of details. On the other hand, a particular interest may be taken in their interactions. The two subsystems are in constant interaction through several business events. This coupling makes possible investigating different transition scenarios and analyse their impacts on the sustainable performance of production subsystem, decomposed in economic, environmental and societal externalities. Performance analysis has to emphasize the existence (or not) of balancing mechanisms between decision levers associated to each subsystem (capacity management and PSS offer engineering).

\subsection{User-Oriented Subsystem}

This subsystem represents behavioural aspects of the customers. Two main types of behaviours are modelled: the commercial behaviours leading to PSS purchase decisions; and utilization behaviours which notably generate strong variations in needs of services triggered along the product lifecycle.

We adopt stochastic representation to model market and utilization behaviours. The commercial behaviours is characterized by different kinds/families of markets and/or customers (professional or not, exigent or not, intense use or not...). Thus, this 
subsystem represents the global behaviour of the market, and the commercial behaviour of the customer with regards to the PSS market offer. The variables represent the decision levers associated to the PSS offer engineering: price, contract term, servicemix, service quality... Then, the utilization behaviours depend on different characteristics, also represented by variables: characteristics of the product, of the user and of the use processes. During the PSS lifecycle, all these variables influence the level of product solicitations and so the needs of service providing.

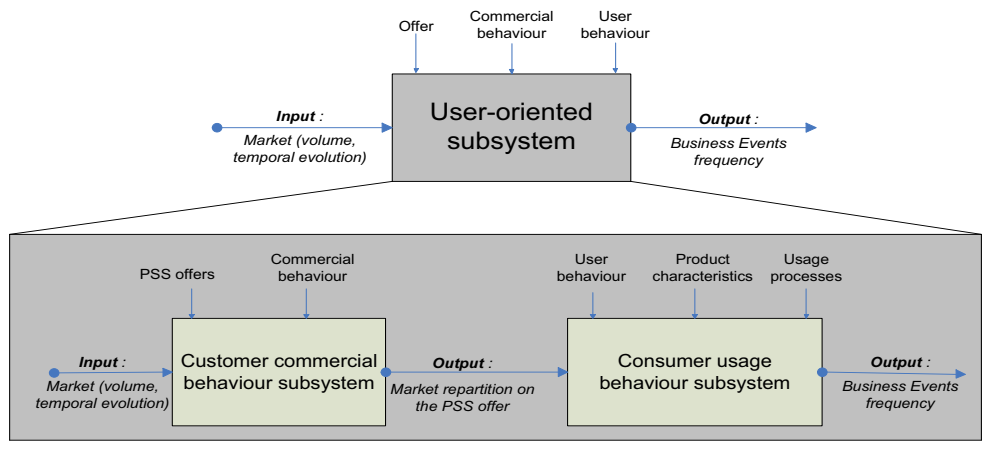

Fig. 1. Global view of the user-oriented subsystem model

\subsection{Production Subsystem}

The production-oriented subsystem represents a set of services providing, manufacturing and remanufacturing processes. It is dedicated to model both manufacturingoriented and service-oriented processes. It is built on a discreet-event simulation approach distinguishing two classical horizons: strategic and operational decisions.

From a strategic point of view, the model is focused on the DM's behavior with regards to the capacity balance strategy. Different DM's planning strategies have been identified: (i) Chasing strategy (the capacity is adapted to the demand), (ii) Stable strategy (the capacity level is kept constant and proportional to the average demand), and (iii) Smoothing strategy (demand variation may be anticipated). The 3 strategies may be added to stock-out acceptation or subcontracting strategies.

From an operational perspective, the objective is to represent the daily decisionmakers's behavior towards the resources balancing. In a context where the global capacity level is fixed (by strategic decision), managers have to establish resources jobs affectations. Resources are defined by a set of competencies. A first level of strategy concerns the priority between production and services providing operations. Then, different behaviors may be modeled in term of resources affectation (\% of utilization, competency level, cost per hour...).

\section{$4 \quad$ Case Study}

ENVIE is a French enterprise in the Waste Electrical and Electronic Equipment (WEEE) sector. ENVIE is committed to conducting every aspect of its business in a responsible and sustainable manner. This includes being a work-integration social 
enterprise. ENVIE covers whole French territory through a local Small and Medium Enterprises (SME) network. This study particularly focuses on a regional dimension of the enterprise (17 persons). Choosing this company to support this feasibility study presents a twofold interest: (i) a strategic question relative to PSS adoption by ENVIE, and (ii) the sustainable orientation of the enterprise. The target is to emphasize the interest (or not) for the PSS transition, through a simulation and analysis of the performance of the production system. This case study will be used to demonstrate: (i) the feasibility and the relevance of the modelling approach, and (ii) the kind of results, analyses and decision support provided by the model.

\subsection{User-Oriented Sub-system}

We model the market through the evolution of a specified product family (VPF,t). "washing machines". The market will be decomposed into two segments, classical selling (VC,t) and PSS (VPSS,t), that represent the temporal evolution of the PSS or classic customer volumes. Different PSS customers' commercial profiles are distinguished. The distribution of all PSS customers on different commercial profiles is represented by a discrete probability distribution $\alpha \mathrm{i}$ and associated with each commercial profile Pcomi as $\Sigma \alpha i=1$. Each contract offer (OC)i is defined by: (i) a type of product TPi,(ii) a bundle of services $\{\mathrm{Sk}\} \mathrm{k}=1, \mathrm{p}$ and (iii) a service quality $\mathrm{SQ}$. The company brings to market a portfolio of contracts offers, denoted: $\{(O C) j\} j=1, n$ / $(\mathrm{OC}) \mathrm{j}=(\mathrm{TPi},\{\mathrm{Sk}\} \mathrm{k}=1, \mathrm{p}, \mathrm{SQ})$. Commercial profiles $(\{\mathrm{Pcomi}\} \mathrm{j}=1, \mathrm{q})$ describe users' behavior when selecting a specific contract offer among $\{(\mathrm{OC}) \mathrm{j}\}$. The purchasing decision process is represented stochastically where each commercial profile is associated to a discrete random variable denoted $\operatorname{Disc}(\mu \mathrm{q}, \mathrm{n})$. This last one traduces the attraction of a commercial profile (q) to a type of offer (n).

To simulate user behaviors, this study focuses on the washing machine utilization process which affects the demand for maintenance services. A set of variables is used to represent stochastically various user utilization profiles.

The simulation of this user-oriented sub-system provides a set of demand signals, which can be utilized afterwards as input to simulate the production sub-system. By simulating commercial as well as usage behaviors, we finally generate stochastically various demand signals for service operations: 'delivery and installation', 'maintenance and repair' and 'take back' services.

\subsection{Production Subsystem}

In this feasibility study we focus on analyzing internal logistic regulation parameters to manage the variability generated by service demands: the impact of affectations rules and resources competencies on the industrial performance.

We consider two types of product called Pf1 and Pf2 respectively characterized by high and medium quality levels. Pf2 is a remanufactured product. Product was assembled with three parts (A, B and C). For Pf1, only new parts are used. For Pf2, reused parts called A', B', C' are used. In case of inventory stock out, new parts (A or B or C) can be used to assembly Pf2. The manufacturing system is composed by 3 workstations (Fig. 2). The 3 operations have to be made in sequence. 


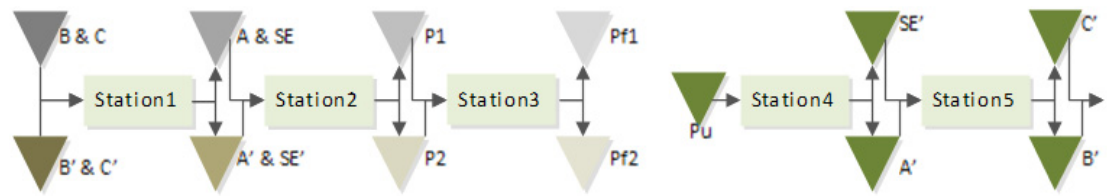

Fig. 2. Production routing sequence

Fig. 3. Remanufacturing routing sequence

Products are remanufactured through disassembly, test, repair, refreshing, reassembly, and packing operations. We consider that the remanufacturing can be decomposed on the two sub-processes (Fig. 3). The disassembly line is composed by two stations. The disassembly sequence is the reverse of the assembly routing sequence.

We consider in this paper a list of potential services: Selling, Product Delivery (including installation), Maintenance (including repairing) and product Take-Back. All the processes necessary to deliver these services are represented through a simulation model. Each service is modeled as an operational process which uses resources (during a given time). Each resource is characterized by a flexibility level which authorize or not the resource to be used to provide a service.

\section{Simulation}

The results presented are the average results of 20 replications and the Simulation duration is 4 years. In our simulation, we consider that company provide four different contract offers $(\mathrm{OC}) \mathrm{j}=1 . .4$. For this paper, we consider 3 performance indicators: (i) Service Level (SL), assessed by the average time of response maintenance and average time of service delivery, (ii) Inventory Level, and (iii) Rate of use of resources. We consider three commercial profiles $(\{P c o m i\} j=1,2,3)$ with two scenario of the distribution of PSS customers on different commercial profiles $\alpha 1 \mathrm{i}$ and $\alpha 2 \mathrm{i}$.

2 contract durations, 2 affectation rules (priority to Production "P-R-S" or to Service "S-R-P") and 2 situations of resources skills (Flexibility "F", Specialization "Sp") have been defined. So, we have 6 scenarios, which are analyzed in the 2 situations (distribution of commercial profiles), which gives us a total of 12 scenarios (table 1):

Table 1. Scenarios simulated

\begin{tabular}{|c|c|c|c|c|}
\hline Scenarios & $\alpha_{i}$ & Contractduration & Resources & Affectation \\
\hline Sce 1.1 $\left(\alpha^{1}{ }_{i}\right) /$ Sce $2.1\left(\alpha^{2}{ }_{i}\right)$ & \multirow{6}{*}{$\begin{array}{c}\alpha_{i}^{I}=(0.2 \\
.4,0.4)\end{array}$} & 1 year & $\mathrm{F}$ & P-R-S \\
\hline Sce $2.1\left(\alpha_{i}^{1}\right) /$ Sce $2.2\left(\alpha^{2}{ }_{i}\right)$ & & 2 years & $\mathrm{F}$ & P-R-S \\
\hline Sce 3.1 $\left(\alpha_{i}^{1}\right) /$ Sce $2.3\left(\alpha_{i}^{2}\right)$ & & 1 year & $\mathrm{F}$ & S-R-P \\
\hline Sce $4.1\left(\alpha_{i}^{1}\right) /$ Sce $2.4\left(\alpha^{2}{ }_{i}\right)$ & & 2 years & $\mathrm{F}$ & S-R-P \\
\hline Sce $5.1\left(\alpha_{i}^{1}\right) /$ Sce $2.5\left(\alpha_{i}^{2}\right)$ & & 1 year & $\mathrm{Sp}$ & ---- \\
\hline Sce 6.1 $\left(\alpha_{i}^{1}\right) /$ Sce $2.6\left(\alpha_{i}^{2}\right)$ & & 2 years & $\mathrm{Sp}$ & ---- \\
\hline
\end{tabular}




\section{$6 \quad$ Results and Interpretations}

The following Fig. 4, 5 and 6 give the influence of commercial profile distribution and contract duration on service performance using the indicators described in Table 2. We note that the distribution of commercial profiles affects the services performance (Fig. 4) for all scenarios, we note that in the case of a specialization of resources, service performance are better in the case of $\alpha 2$ (we have $13 \%$ of gain for maintenance reaction times and $25 \%$ for the delivery time). For the influence of contract duration on service performance, we note that the duration contract of 2 years allow the company to reduce the response time for delivery and maintenance reaction (Fig. 5). The Fig. 7 gives the influence of resources skills on service performance using the indicator. We note that in both cases $(\alpha 2, \alpha 1)$, giving the priority to service, allows company to reduce the delivery time and maintenance reaction time. The Fig. 8 gives the average resource utilization rate. We note that in both cases, the average rate is substantially identical. In scenario 3 and 4, resources are less utilized, because priority is given to the services, and therefore the resources are allocated to services, the execution time and demand are less important than the production process and remanufacturing. To overcome this problem of unavailability of certain resources for the production process and remanufacturing when priority is given to service, the system draws the finished product stock as shown in Fig. 9. The stock is used to allow some resources to support service activities.

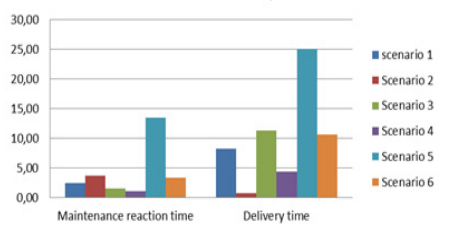

Fig. 4. Influence of commercial profile repartition (Pcom repartition)
Table 2. Formula of calculation of indicators

\begin{tabular}{|c|c|}
\hline & Indicator \\
\hline Fig 5 & $\forall i \in(1 ; 3 ; 5), \frac{\left(\text { SL }\left(\text { scenario }_{i}\right)\right)-\left(\text { SL }\left(\text { scenario }_{i}\right)\right)}{\left.\left(\text { SL }_{\left(\text {scenario }_{i}\right.}\right)\right)} \times 100$ \\
\hline Fig 6 & $\forall i \in(1 ; 3 ; 5), \frac{\left.\left(\text { SL }_{\text {scenario }}\left(\alpha^{1}\right)\right)\right)-\left(\operatorname{SL}\left(\text { scenario }_{i}\left(\alpha^{2}\right)\right)\right)}{\left(\operatorname{SL}\left(\text { scenario }_{i}\left(\alpha^{1}\right)\right)\right)} \times 100$ \\
\hline Fig 7 & 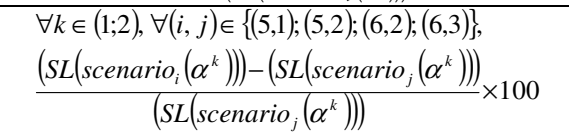 \\
\hline
\end{tabular}

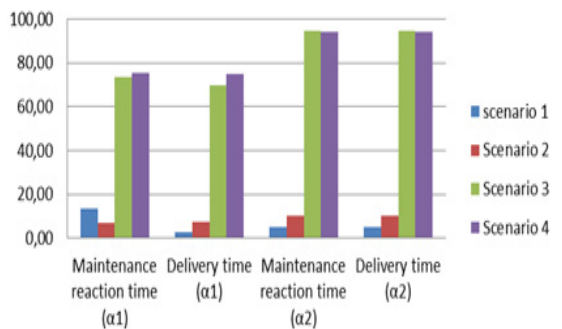

Fig. 5. Influence of Pcom repartition

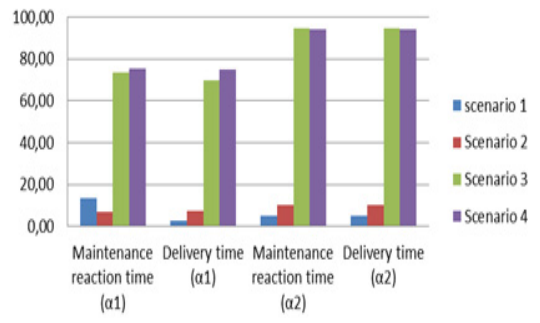

Fig. 6. Influence of resources skills 


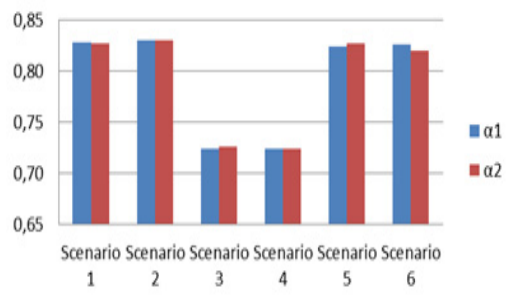

Fig. 7. Average Utilization rate of resources

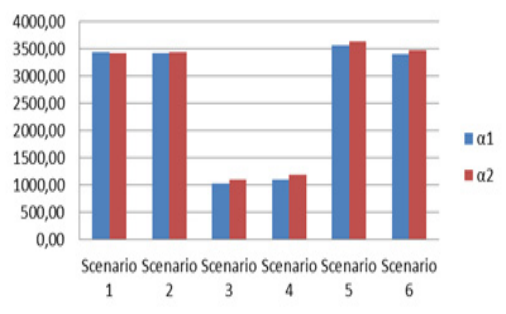

Fig. 8. Average Stock $(\mathrm{Pf} 1+\mathrm{Pf} 2)$

\section{Conclusion and Perspectives}

The study conducted in this paper shows the impact of the commercial offer of the company on the one hand, and on the other hand the impact of the competence based rules for task assignation on business performance. We have to extending further the coupling between the User-oriented subsystem and the productions subsystem to find rules of resource management for a given commercial offer situation.

\section{References}

1. Baines, T.S., Lightfoot, H.W., Evans, S., Neely, A., Greenough, R., Peppard, J., Roy, R., Shehab, E., Braganza, A., Tiwari, A., et al.: State-of-the-art in product-service systems. Proceedings of the Institution of Mechanical Engineers, Part B: Journal of Engineering Manufacture 221, 1543-1552 (2007)

2. Hockerts, K.: Eco-Efficient Service Innovation: Increasing Business-Ecological efficiency of Products and Services. In: Charter, M. (ed.) A global Perspective on Greener Marketing Practice. Gereenleaf, Pub., Sheffield (1999)

3. Komoto, H., Tomiyama, T., Nagel, M., Silvester, S., Brezet, H.: Life Cycle Simulation for Analyzing Product Service Systems. In: Fourth International Symposium on Environmentally Conscious Design and Inverse Manufacturing, Eco Design 2005, pp. 386-393 (2005)

4. Phumbua, S., Tjahjono, B.: Towards product-service systems modelling: a quest for dynamic behav-iour and model parameters. International Journal of Production Research 50, 425-442 (2012)

5. Kowalkowski, C.: Managing the industrial service function (2008)

6. Wangphanich, P.: Simulation model for quantifying the environmental impact and demand amplification of a Product-Service System (PSS). In: 2011 International Conference on Management Science and Industrial Engineering (MSIE), pp. 554-559 (2011)

7. Bianchi, N.P., Evans, S., Revetria, R., Tonelli, F.: Influencing Factors of Successful Transitions towards Product-Service Systems: a Simulation Approach. International Journal of Mathematics and Computers in Simulation 3, 30-43 (2009)

8. Mont, O.K.: Clarifying the concept of product-service system. Journal of Cleaner Production 10, 237-245 (2002)

9. Guide, V.D.R.: Production planning and control for remanufacturing: industry practice and research needs. Journal of Operations Management 18, 467-483 (2000)

10. Mathieu, V.: Service strategies within the manufacturing sector: benefits, costs and partnership. International Journal of Service Industry Management 12, 451-475 (2001)

11. Olhager, J., Rudberg, M., Wikner, J.: Long-term capacity management: Linking the perspectives from manufacturing strategy and sales and operations planning. International Journal of Production Economics 69, 215-225 (2001) 